\title{
Analysis of damaging seismic event on 24 December 2011 in the Pilar Norte sector of El Teniente mine
}

\author{
D Malovichko Institute of Mine Seismology, Australia \\ D Cuello Newcrest Mining Limited, Australia \\ E Rojas Codelco, Chile
}

\begin{abstract}
Numerous tunnels of the extraction and undercut levels of the Pilar Norte sector experienced violent damage on 24 December 2011. A seismic event with a moment magnitude of 2.4 was recorded by the mine-wide seismic system at the same time. It is difficult to explain the observed damage with peak particle velocities/peak ground velocities calculated for the basic source parameters of this event (location and magnitude).

Seismic data recorded in Pilar Norte in 2011 indicate that failure in the sources is driven by sub-vertical compressional stress. The majority of seismic events located around the undercut level have crush-type source mechanisms (significant implosive component, pancake-shaped deviatoric parts with sub-vertical P-axis) evidencing vertical convergence of the excavations. There are no clear indications of active planar geological structures in the seismic data.

The large seismic event that occurred on 24 December 2011 during the blasting sequence and its waveforms are complex. The source mechanism estimated from the low frequency part of the waveforms is of a crush-type. It was hypothesised that the source of this event represents a cascading damage of tunnels. The hypothesis was tested by means of comparing the modelled waveforms of spatially distributed episodes of tunnel damage with the recorded waveforms. A reasonable match was obtained for the scenario including an initial $20 \mathrm{~mm}$ convergence of the extraction and undercut drives around the southern Pilar Norte undercut front at a rate of $0.6-0.8 \mathrm{~m} / \mathrm{s}$ and subsequent spread of smaller $(3-6 \mathrm{~mm})$ convergence along the eastern Pilar Norte undercut front and eastern Sub 6 cave abutment at a rate of $0.2-0.4 \mathrm{~m} / \mathrm{s}$. There was also significant shearing (ride) deformation along the southern and eastern Pilar Norte cave front.

The hypothesis of cascading damage of tunnels also agrees with the underground observations (more than $90 \%$ of damage was attributed to the side walls of tunnels) and predictions of sub-vertical orientation of maximum principal stress around the tunnels of the extraction level according to a numerical stress model.
\end{abstract}

Keywords: seismic source mechanism, mechanism of damage, cascading damage of tunnels

\section{Introduction}

It is typical to have a situation at underground mines when a large seismic event is recorded by a seismic system at the same time that damage occurs in underground excavations. In spite of the co-occurrence of a seismic event and damage, the correlation between the parameters of seismic sources (location and magnitude) and damage is vague in some cases. The peak particle velocities (PPV)/peak ground velocities (PGV) calculated at the places of damage using ground motion prediction equations (scaling laws) are too small to explain the damage by the impending stress wave. There may be several reasons for this.

Firstly, the location of the seismic source may not be accurate. Large seismic events quite often have complex waveforms and picking the arrivals of seismic waves can be challenging. The coverage of the source by seismic sites can also be limited. These factors may contribute to significant uncertainty of the source location, and it is possible that the damage can be located within or very close to the location confidence region. In such cases, it is useful to test the possibility of co-location of the seismic source and source of damage by 
comparing the observed arrival times of seismic waves with the arrival times calculated, assuming that the damage represents a seismic source.

Secondly, the finite source size may not be properly accounted for. The distance to the place of damage is measured from the location of the seismic source, which is typically based on the first arrivals of P- and S-waves. It is quite common that damaging events have complex waveforms which can be attributed to the source, rather than to the medium through which the seismic waves propagate. The recorded waveforms of complex events may not be explained by the radiation of seismic waves from the same location. It is more likely to have a situation where the seismic waves are radiated from different locations, indicating that the seismic source consists of several spatially distributed sub-sources. This finite spatial extent needs to be taken into account when the damage is analysed, i.e. while the place of damage may be far from the location of seismic source initiation, it can be close to (or even co-locate with) the subsequent sub-sources. Note that in engineering seismology, the hypocentral distance is not a preferred measure of proximity of the site of interest to the earthquake source and other measures are considered as more suitable (Bolt \& Abrahamson 2003), e.g. rupture distance (closest distance to the rupture surface) or Joyner-Boore distance (shortest horizontal distance to the vertical projection of the rupture).

It is useful to mention here the similarities of definitions of a seismic event and rockburst. A seismic event represents "a sudden inelastic deformation within a given volume of rock that radiates detectable seismic wave" (Mendecki 1997). Rockburst is defined as a "damage to an excavation that occurs in a sudden or violent manner and is associated with a seismic event" (Kaiser et al. 1996). It is valid to say that sudden or violent damage to an excavation always radiates seismic waves which can be detected (provided that the seismic monitoring system is sensitive enough). Therefore, such damage to an excavation always represents a seismic source and additional reference to a seismic event in the definition of rockburst ("and is associated with a seismic event") is not required. It is possible to have a scenario in which the seismic radiation from rockburst explains the recorded seismic waveforms completely, and as such, the rockburst can be classified as self-initiated (Section 2.2 of Kaiser et al. 1996). An alternative scenario is that seismic radiation from the rockburst may be hidden among the larger seismic signals emanated by some other, stronger episode of sudden inelastic deformation. The latter can represent slip along a fault and, therefore, the rockburst will be classified as remotely induced or triggered.

The last reason is that PPV/PGV is not the only ground motion parameter that can be used to explain damage. For example, a variety of measures of intensity of ground motion are used in engineering seismology and it is advocated that the appropriate measure of intensity needs to be selected for design according to the anticipated mechanism of damage. Following this logic, we can say that PGV may not be a useful measure of ground motion for all variants of violent damage of excavations. For example, taking into account that strainbursting is controlled by a tangential straining on the perimeter of an excavation, it may be better to consider the effect of the seismic event to the excavation not in terms of PGV, but in terms of transient (dynamic) and residual (static) tangential strain.

The aim of this paper is to explore and illustrate the aforementioned aspects of the relation between seismic source and damage using a large seismic event that occurred at the Pilar Norte sector of El Teniente mine in December 2011.

A description of El Teniente mine and mining-induced seismicity can be found in other publications (e.g. Rojas \& Balboa 2017). The geology and mining of Pilar Norte will be briefly discussed here.

\section{Geology, stress field and mining method}

The geology of the Pilar Norte orebody is complex and characterised by the presence of felsic intrusives and hydrothermal breccias. The unconfined compressive strength (UCS) for all these units vary between 120 and $145 \mathrm{MPa}$. The main lithological features shown in Figure 1 can be classified as massive and competent. The white colour represents andesite, the diorite is shown in violet, the andesitic porphyry is red, and the breccias are in dark blue and green. The diorite, andesitic porphyry and breccia have quite different mechanical properties compared with the host andesite rock and have been a source of large seismic events. Mainly, 
two types of discontinuities are present in this sector - large-scale faults (shown in blue in Figure 1) and a stockwork of small-scale veins which are mainly cemented with quartz, sulphides and anhydrite.

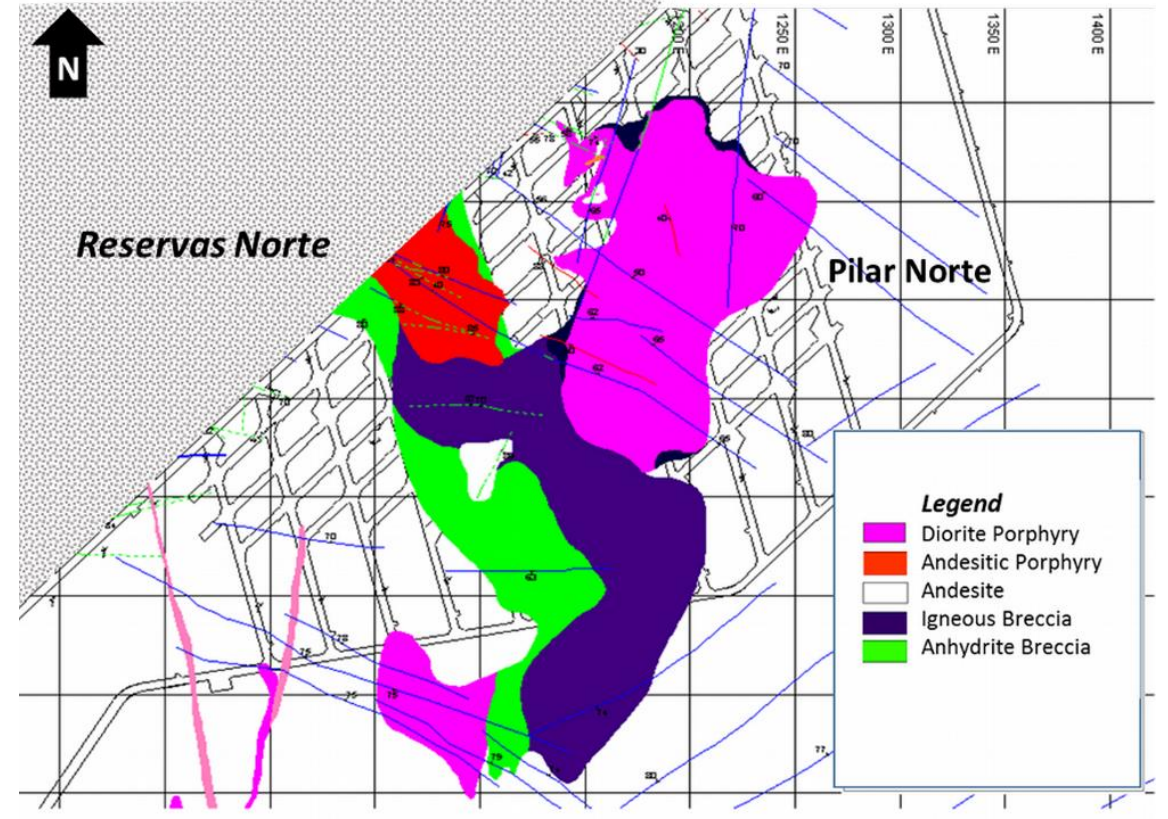

(a)

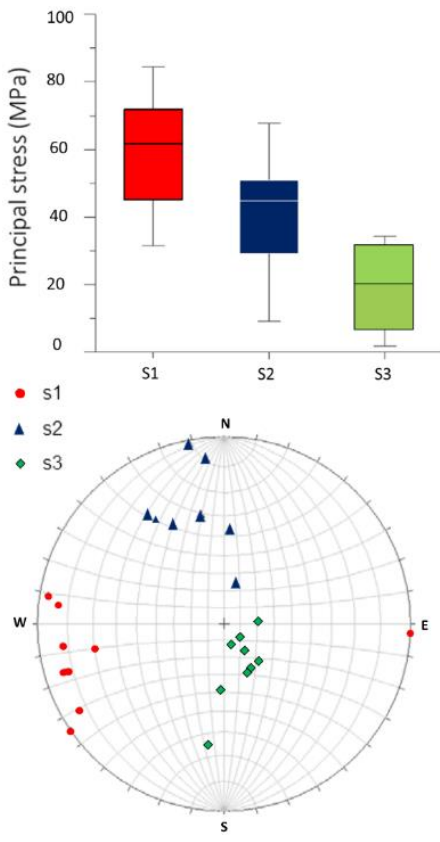

(b)

Figure 1 (a) Pilar Norte rock types/lithologies present at the extraction level; and, (b) Magnitudes and directions for in situ principal stresses in Pilar Norte

The pre-mining stress field in the Pilar Norte is complex due to the tectonic and residual stress, as well as the influence of the subsidence craters of both Esmeralda and Reservas Norte. The major principal stress is sub-horizontal and oriented east-west. The minor principal stress is sub-vertical. As shown in the graph presented in Figure 1, the stress field in Pilar Norte can be classified as high and anisotropic.

Mining in Pilar Norte commenced as an advance undercut in August 2009 at the same elevation of Reservas Norte. The growth of the undercut/drawbell incorporation started in the south-southeast direction. Advance undercutting was done using the John Wayne technique (Leiva \& Duran 2003; left in Figure 2). In December 2010, due to the severe damage in the undercut tunnels, the implementation of the 'high drawbell' design was required to continue the cave establishment process. The high drawbell design was aimed to undercut and establish the drawbell ahead of the undercut front by drilling and blasting from the extraction level (right in Figure 2). In Pilar Norte, the spacing of the undercut drives was $20 \mathrm{~m}$, whereas the spacing of the extraction drives was $30 \mathrm{~m}$.

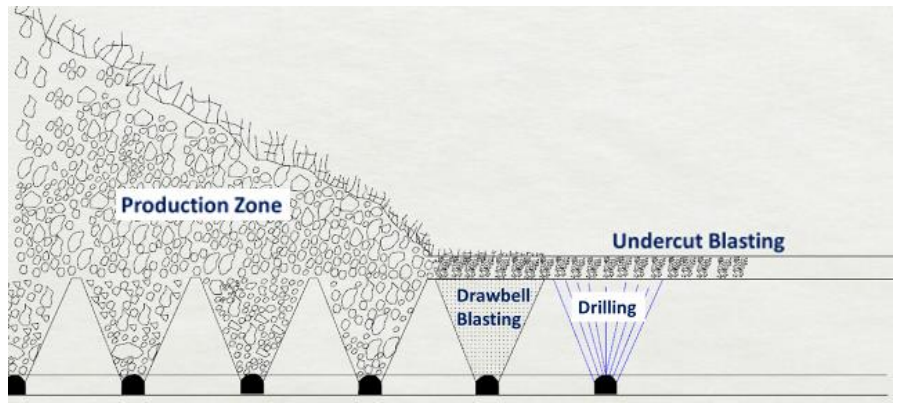

(a)

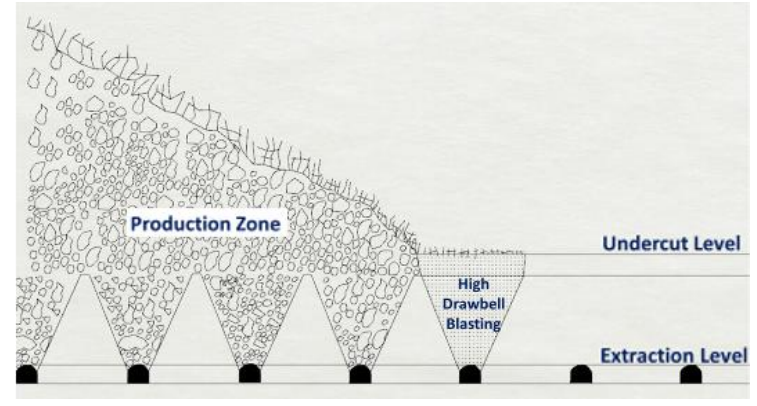

(b)

Figure 2 (a) Advance undercut; and, (b) High drawbell designs 


\section{Rockburst on 24 December 2011}

The violent damage that occurred on 24 December extended over a distance of $315 \mathrm{~m}$ in the east-west direction and $135 \mathrm{~m}$ in the north-south direction. The damage area encompasses $513 \mathrm{~m}$ of tunnel damage with $50.5 \%$ of damage classified as level $1,42.3 \%$ as level 2 and $7.2 \%$ as level 3 according to the scale, which is adopted at El Teniente mine and based on rehabilitation requirements. The examples of the intensity of damage per damage level are shown in Figure 3.

Level 1

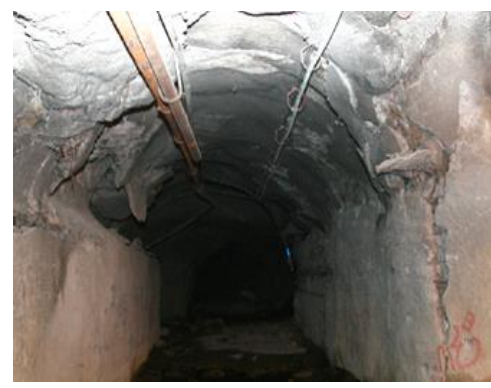

Replacement of surface ground support elements is required
Level 2

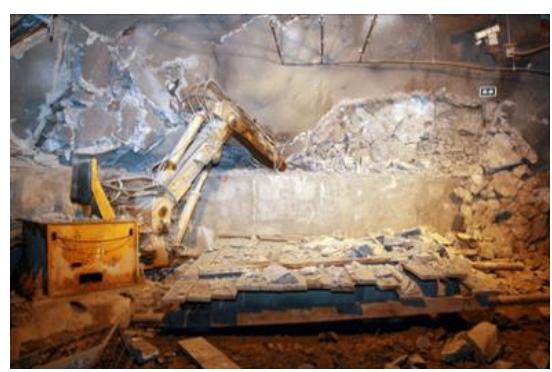

Surface and reinforcement elements need to be replaced
Level 3

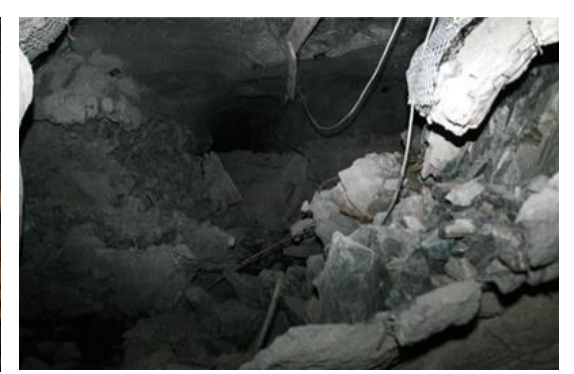

All support elements have been compromised. Rehabilitation is not possible sometimes or techniques such resin injections are required before attempting rehabilitation

\section{Figure 3 Examples of damage levels observed during the rockburst}

The damage occurred across the undercut (24\%), extraction (66\%), transportation (2\%), intermediate transportation (3\%) and ventilation (4\%) levels mainly along the abutment of Pilar Norte and Sub 6 caves. No damage was reported in the extraction level under the caves. The range of damage included back, wall and shoulder rockfalls, ejection and cracking of fibrecrete, and floor heave. Damage in the walls and shoulders of the drives accounted for more than $95 \%$ of all affected locations. The roof of excavations was generally intact and fall of ground took place in only a few locations.

A 3D elastic numerical modelling was built in Map3d (Wiles 2010) in order to investigate the induced stress changes due to mining inside Pilar Norte. The locations where damage was recorded were compared with the predicted induced stress (Figure 4).

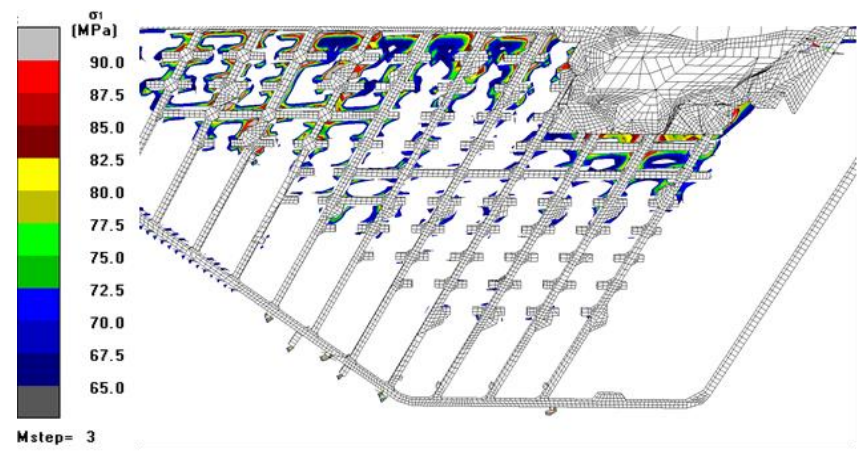

(a)

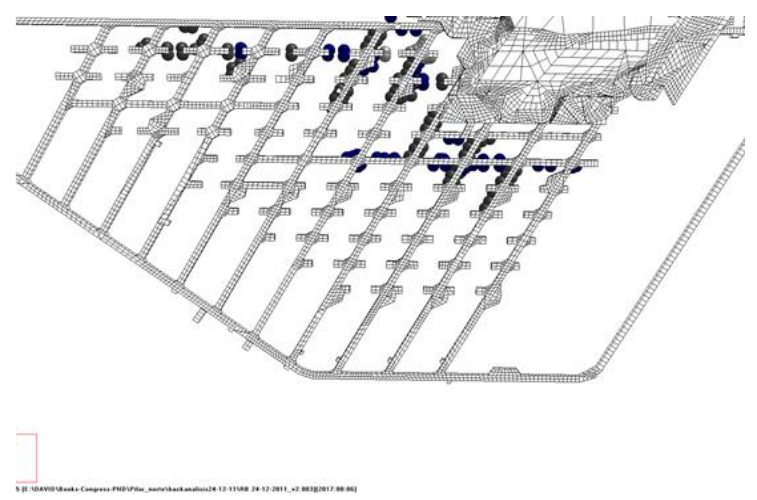

(b)

Figure 4 (a) Modelled stress prediction; and, (b) Location of damage in the extraction level 
When comparing the modelled stress with the recorded damage locations, the following points could be established:

- Maximum principal stress $\sigma_{1}$ was found to be sub-vertical in all damage locations.

- The magnitude of the $\sigma_{1} /$ UCS ratio was found to be a good indicator for areas that experienced damage.

- The magnitude of the $\sigma_{1} /$ UCS ratio could also be related with the damage level. A ratio of 0.62 in the model correlated well with level 1 damage, while ratios over 0.67 and 0.80 were required to match the location of level 2 and level 3 damage, respectively.

\section{$4 \quad$ Characteristics of seismicity recorded in the Pilar Norte sector in 2011}

The El Teniente seismic system provides good coverage of the Pilar Norte sector. There are a number of seismic sites located at Teniente 8 Level below the area of interest, and several sites installed in long holes in the eastern part of the sector. All of these are within the line of sight from the main seismogenic areas in Pilar Norte and, therefore, the recorded waveforms have clear arrivals of direct P- and S-waves. The orientation settings of seismic sites were checked using seismic data, and sites with unreliable settings were excluded from the advanced analysis of waveforms (evaluation of seismic source mechanisms).

Seismic data recorded in 2011 was analysed. Figure 5 summarises the results. The top plots show the spatial distribution of events with moment magnitude (Hanks \& Kanamori 1979) $\mathrm{m}_{\mathrm{HK}} \geq 0.0$ recorded by at least 12 sites and located within the region contoured by blue wireframe. There were 1,390 events that passed these filters and these are displayed as spheres coloured according to time. The source mechanisms of 153 events located above the undercut level are shown as beach balls with red vectors indicating $\mathrm{P}$-axes. The stereonet plots in the bottom represent equal area lower hemisphere projection of principal axes $(\mathrm{P}, \mathrm{B}$ and $\mathrm{T})$ and nodal plane poles of source mechanisms. The nodal planes are presented only for the subset of mechanisms with a significant double-couple component (marked by green dotted contour in the Hudson's source type plot). The red, yellow and green wireframes in the spatial plots of seismicity represent the undercut, extraction and transportation levels of Pilar Norte, respectively. The brown surfaces describe the caves of neighbouring sectors (Reservas Norte, Esmeralda), and grey lines are their development tunnels.

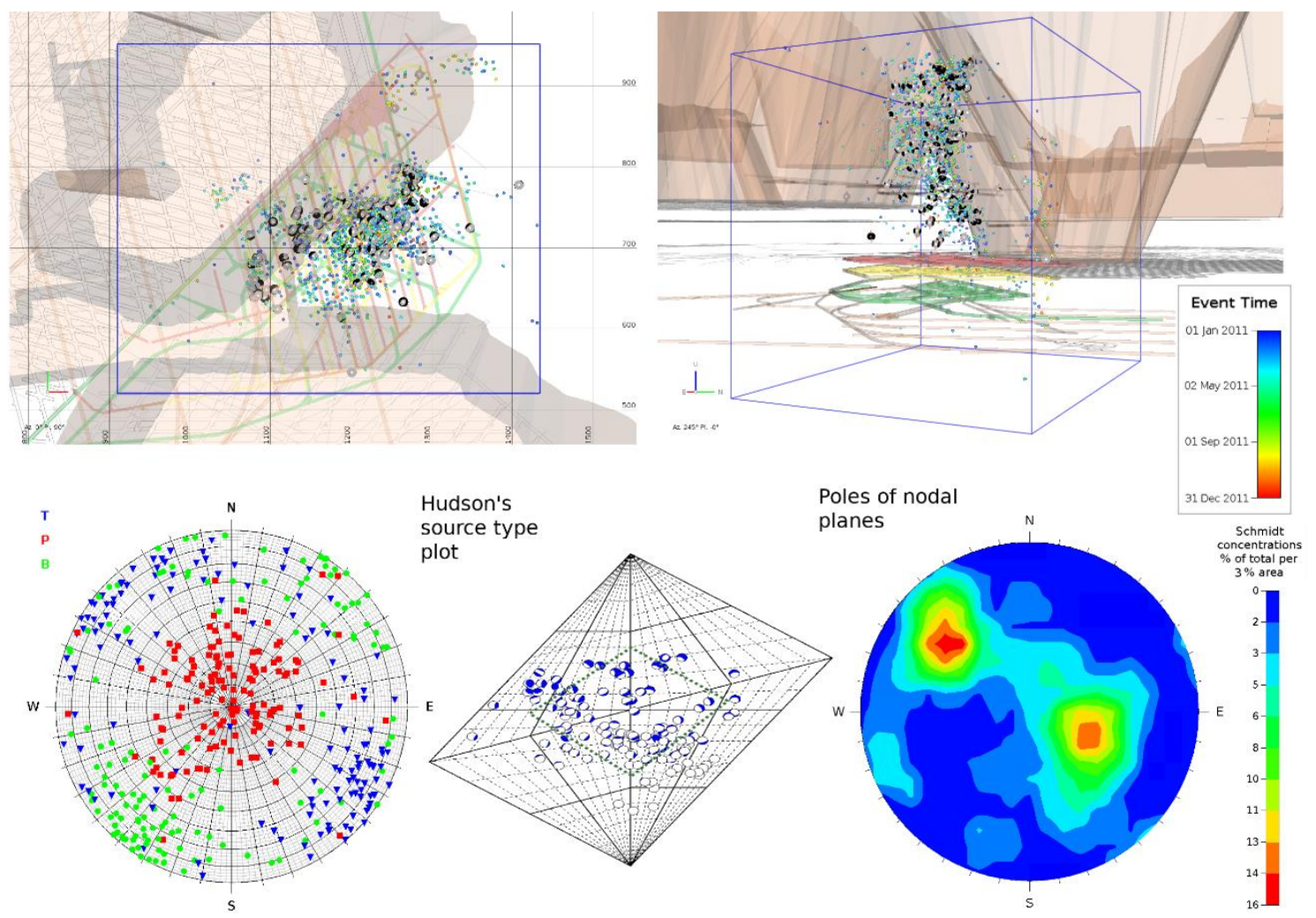

Figure 5 Seismicity observed in the Pilar Norte sector in 2011 
The major portion of seismicity (nearly $89 \%$, according to filters applied in Figure 5 ) is distributed above the undercut level. The source mechanisms were evaluated for 153 of these events. Most of the mechanisms correspond to a normal faulting. The T-axis is trending to the NW-SE, i.e. approximately orthogonal to the abutment of Sub 6 sector. The strike of nodal planes of events with double-couple mechanisms correlates with the trend of south-eastern Sub 6 abutment. The location and source mechanisms of events make it possible to interpret seismicity above the undercut level as gravitational sliding on the south-eastern and southern sides of the Sub 6 and Pilar Norte caves and, possibly, northern side of the Esmeralda cave.

There is not much seismicity attributed to the volume between the undercut and transport levels (less than $11 \%$, according to filters applied in Figure 5). Only a few events are located below the transportation level.

The seismicity recorded between the undercut and transport levels was considered in greater detail (Figure 6). The source mechanisms were evaluated for the 40 largest events. Most mechanisms have sub-vertical P-axis, which indicates that seismicity around production level is also driven by sub-vertical stress (similar to seismicity recorded higher up, above the undercut level). A substantial fraction of mechanisms have significant implosive and 'pancake-shaped' deviatoric components, which are rather attributes to failure in the vicinity of excavations and accompanied by their convergence, than failure in a confined environment (e.g. fault slip or shear failure away from excavations). Several events have significant double-couple mechanisms and the strike of their nodal planes also correlates with the trend of southeastern Sub 6 abutment. There were no events found with reliable locations around or below the transportation level and with source mechanisms with sub-horizontal P-axes (i.e. reverse or strike-slip faulting).

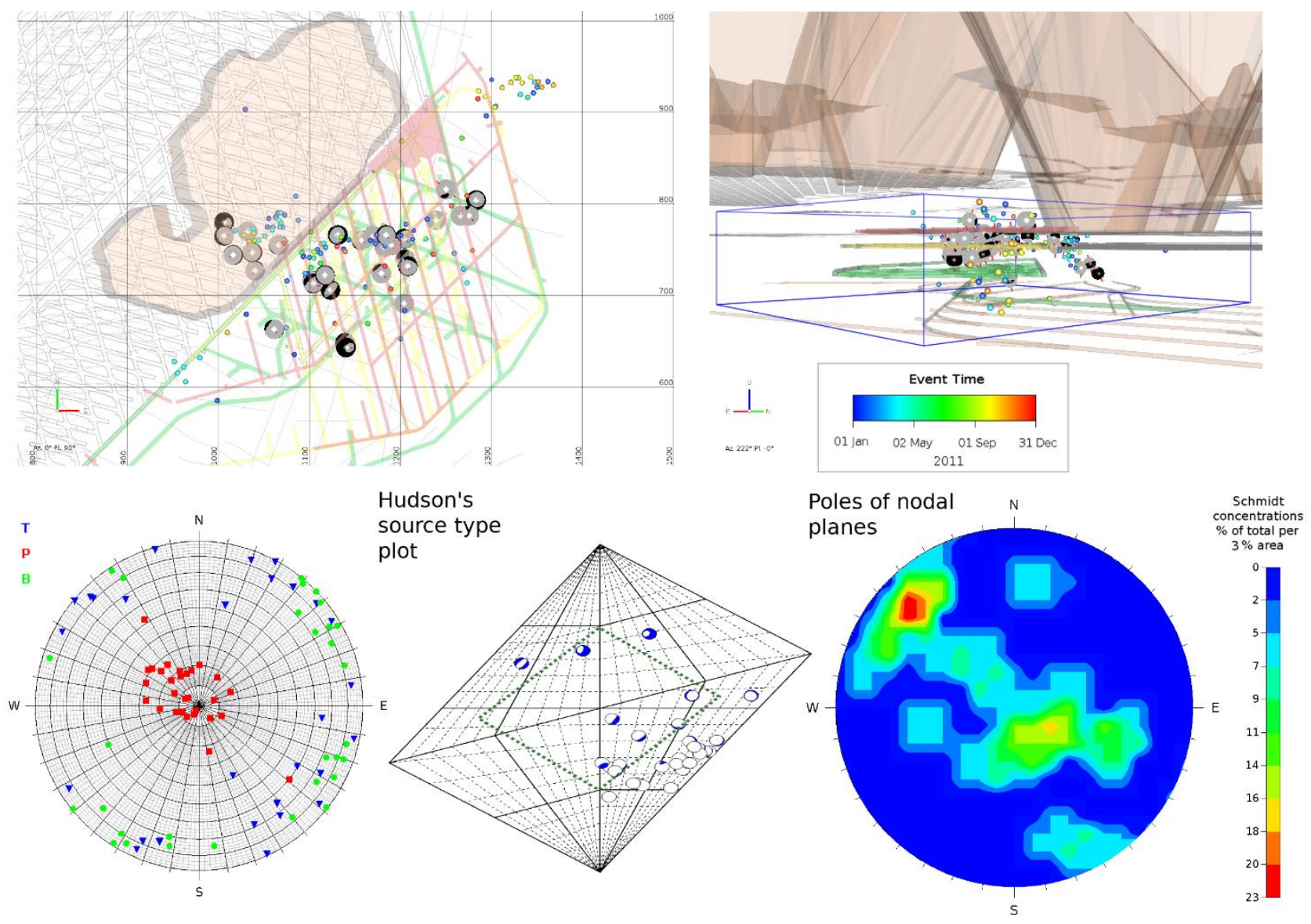

Figure 6 Seismicity observed between undercut and transport levels of the Pilar Norte sector in 2011. The seismic dataset and visualisation settings are the same as in Figure 5 . The only difference is that the spatial filter, shown as a blue wireframe, was applied 
The above-discussed characteristics of seismicity indicate that the dynamic rock mass failure processes happening within the analysed area during the considered period of time are mainly controlled by sub-vertical compressional stress. There are no indications of sudden inelastic deformation occurring around and below the production levels of Pilar Norte, and driven by horizontal compressional stress. It is remarkable that the described pattern of rock mass failure in Pilar Norte is different from the pattern observed in the nearby Sub 6/Reservas Norte sector (200-300 m to the west), where numerous significant seismic events with reverse faulting mechanisms took place below production levels (Dunlop \& Belmonte 2005; Malovichko \& Meyer 2017).

\section{$5 \quad$ Analysis of waveforms of the large seismic event on 24 December 2011}

\subsection{Standard processing}

A large seismic event occurred in the Pilar Norte sector during a blasting sequence at 23:29 on 24 December 2011. The recorded waveforms of the event are complex (Figure 7). Numerous higher frequency signals from firings can be seen before the event. The event itself does not have clear arrivals of P- and S-waves, which makes locating the source problematic.

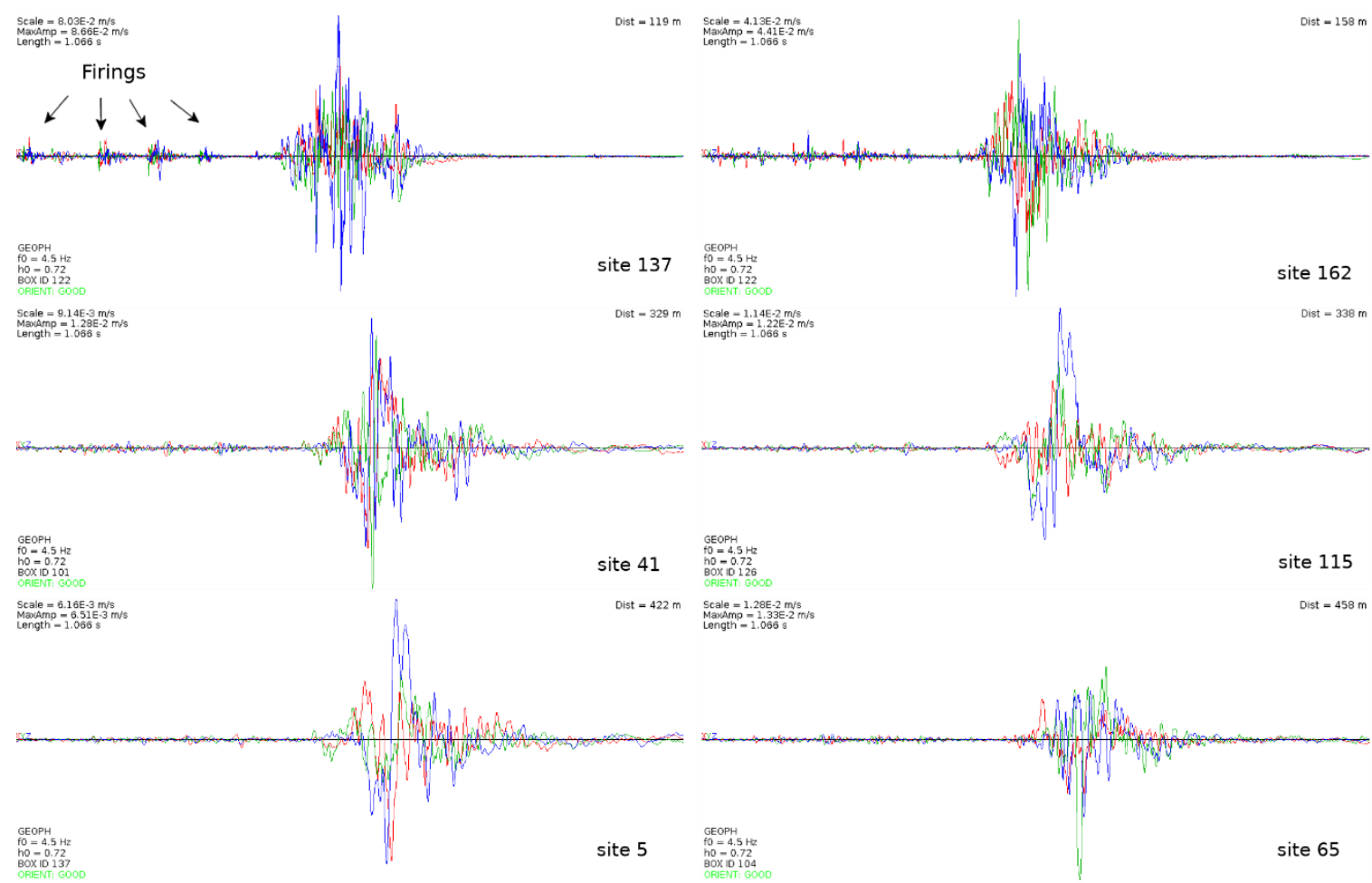

Figure 7 Selected waveforms of the large event on 24 December 2011. Common time scale is used for all seismograms. The amplitude scale is normalised to the maximum amplitude for each seismogram

The source mechanism corresponding to the lowest portion of the spectrum of seismic radiation was evaluated using a full waveform inversion algorithm (method A discussed in Vavrycuk \& Kuhn 2012). The waveforms of displacement in the frequency range from 5-15 Hz were used for the inversion. The algorithm was run for a number of source locations specified on a regular grid. The location and source mechanism providing the smallest difference between the observed and synthetic waveforms were selected as a solution (Figures 8 and 9).

The scalar seismic moment corresponding to the inverted moment tensor is $4.2 \cdot 10^{12} \mathrm{~N} \cdot \mathrm{m}$, which gives the Hanks-Kanamori moment magnitude of 2.4 . 


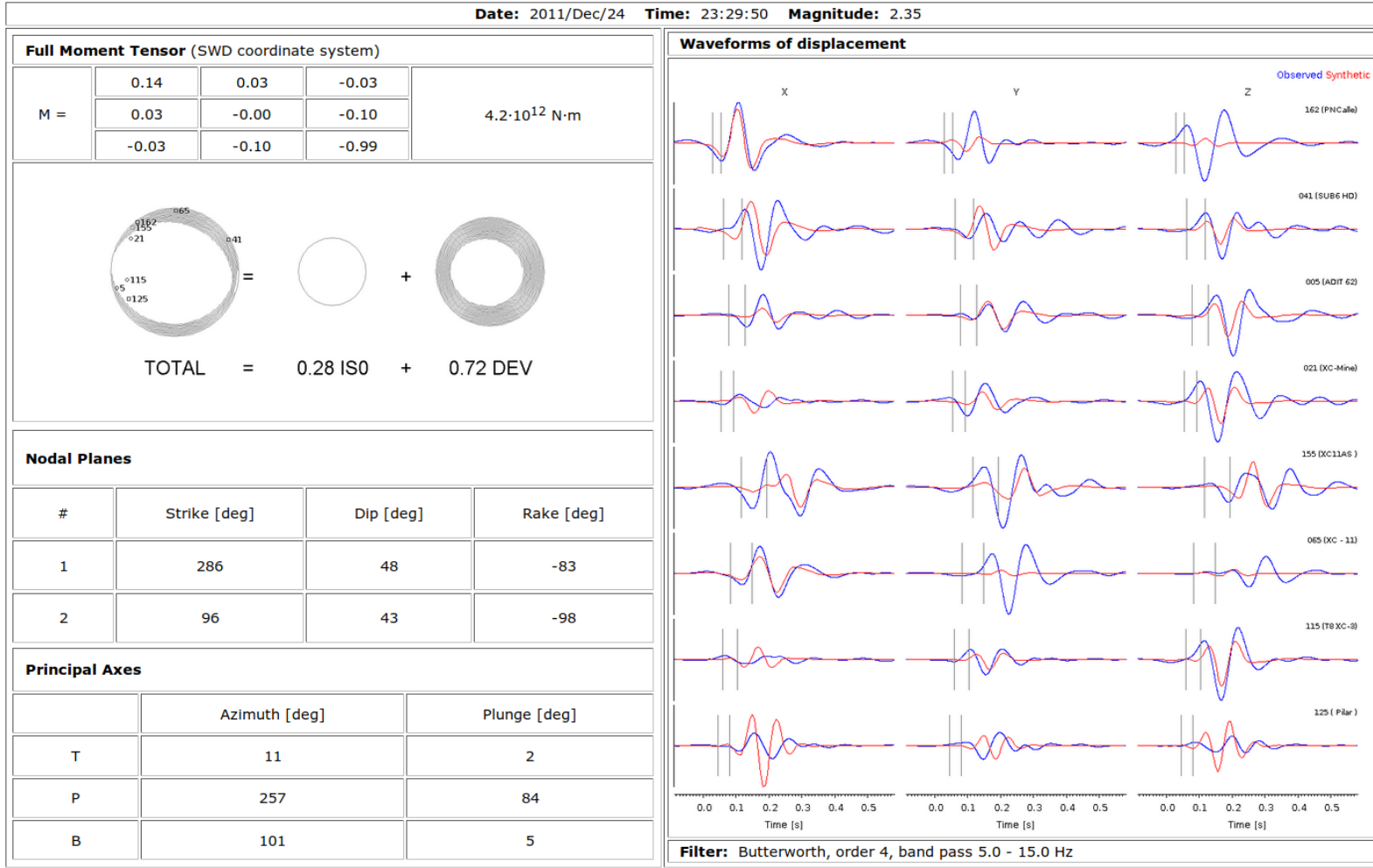

Figure 8 Source mechanism of the large event on 24 December 2011. The inverted mechanism and its parameters are shown on the left. The comparison of the recorded waveforms of displacement with the synthetic waveforms calculated for the inverted mechanism are shown on the right

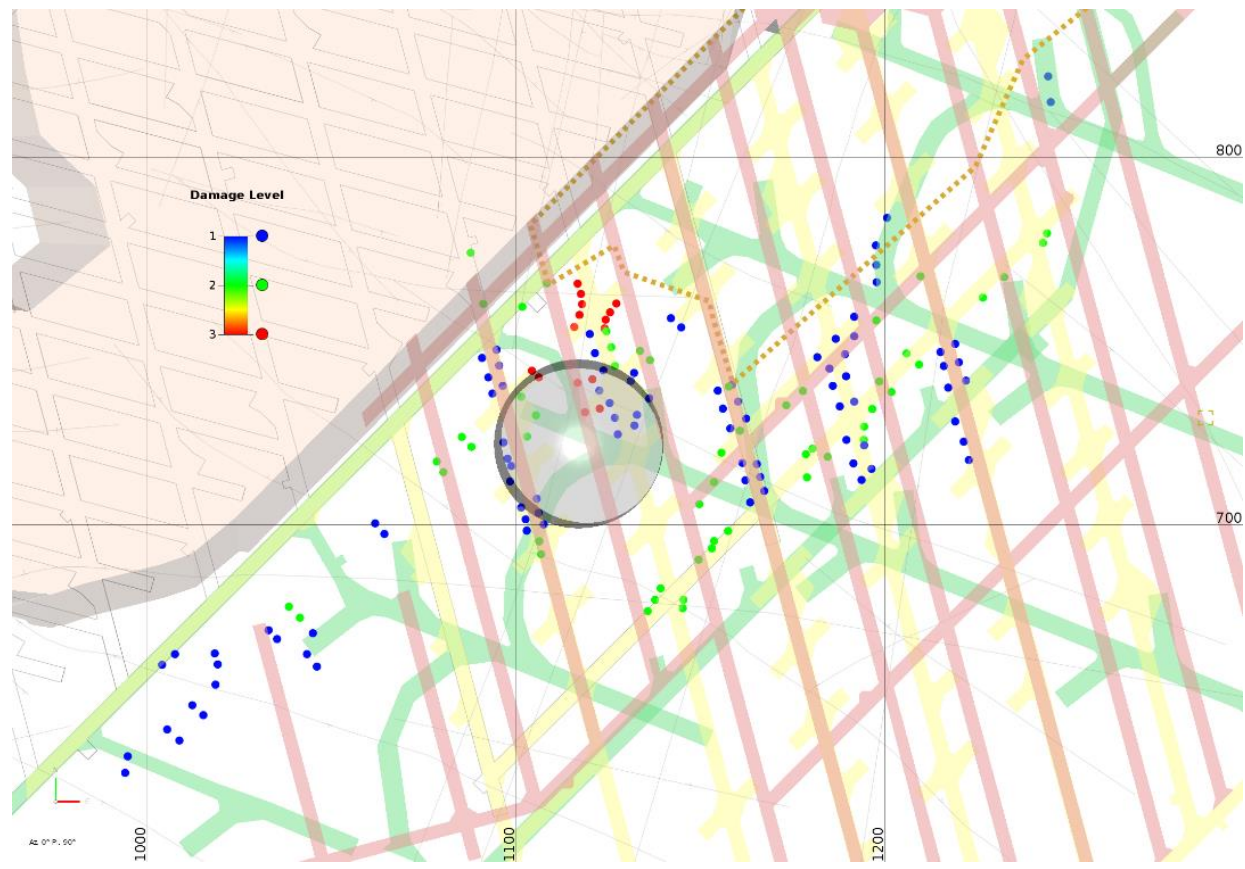

Figure 9 Source mechanism corresponding to a point source and its optimal location (moment tensor centroid) obtained using a full waveform inversion. Dots show the mapped damage, which was mostly observed at the extraction level

The obtained source mechanism has significant implosive component (Figure 8). The deviatoric component is of a 'pancake' shape with sub-vertical P-axis. These characteristics of mechanism are similar to a closing crack model, which is opposite to a tension crack model (Aki \& Richard 2002, p. 51). The closing crack 
model corresponds to a failure of pillar(s) (Malovichko et al. 2012). However, other variants of sudden inelastic deformation which involve convergence of excavations can be described by this point seismic source model too.

The spatial distribution and severity of damage observed underground after the seismic event is shown in Figure 9. The inverted source mechanism of the large event is located within $10-50 \mathrm{~m}$ from the area where the most severe damage was experienced (level 3). However, some level 1 and level 2 damage took place 100-150 $\mathrm{m}$ from that location.

It is difficult to explain the damage in terms of transient stress associated with seismic waves radiated from the point source co-located with the hypocentre of event. For example, the ground motion scaling relation of McGarr (1984; equation 4) predicts a peak ground velocity of $60 \mathrm{~mm} / \mathrm{s}$ at a distance of $100 \mathrm{~m}$ from the source with a seismic moment of $4.2 \cdot 10^{12} \mathrm{~N} \cdot \mathrm{m}$ and $40 \mathrm{~mm} / \mathrm{s}$ at a distance of $150 \mathrm{~m}$. The ground motion scaling relationship number I suggested in Table 1 of Kaiser and Maloney (1997) provides similar values 65 and $43 \mathrm{~mm} / \mathrm{s}$. The magnitude of transient stress pulse associated with an S-wave with such peak amplitudes will be less than $1 \mathrm{MPa}$. It is unlikely that such a pulse may initiate damage in different places simultaneously. The asymmetry of the spatial distribution of damage (extension of damage in the northeast-southwest direction; Figure 9) is also difficult to relate to the parameters of a seismic point source and requires invoking a hypothesis of a very non-uniform radiation pattern.

There is an alternative explanation of the relation between the source of the seismic event and damage. Considering the complexity of recorded waveforms, it is reasonable to assume that the source of the seismic event and the source of damage may be the same thing, i.e. recorded seismic waves were radiated from the cascading damage of tunnels in the undercut and extraction levels. This hypothesis is quantitatively explored in the next subsection by means of inversion of higher frequency parts of recorded waveforms.

\subsection{Reconstruction of finite source characteristics of a large seismic event on 24 December 2011}

The complex nature of the waveforms of the large event (Figure 7) require some comments. The waveforms of smaller events recorded in the same area look much simpler; they generally have clear arrivals of P- and $\mathrm{S}$-waves and relatively small coda waves. This indicates that the complexity of the waveforms of the large event cannot be explained by the effects of the propagation of seismic waves in a heterogeneous medium, e.g. reflection of waves from caves, scattering of waves. This means that numerous impulses observed in seismograms in Figure 7 are rather related to the source of event. These impulses can correspond to seismic radiation from various episodes of failure which have not necessarily occurred at the same location. These failures may be initiated in one location and propagate in space with time.

The complexity of sources is well-known in crustal seismology, where the sources of large tectonic earthquakes may have dimensions of hundreds of kilometres and may take tens of seconds for the rupture to propagate from one part of the source to another. The spatio-temporal distribution of dynamic slip along faults can be reconstructed from the recorded waveforms using the methods known as finite fault slip inversion or, simply, slip inversion (Ide 2007). The slip inversion methods have two major differences compared to the conventional moment tensor inversion, which was employed in the previous section (Figure 8):

- A combination of point sources distributed in space and time is used instead of a single point source.

- Higher frequency waveforms are adopted instead of low-pass filtered waveforms.

In relation to the considered hypothesis about the source of the large event on 24 December 2011, it is of interest to invert not the slip along a plane, but rather the spatial and temporal distribution of convergence in the undercut and extraction levels. To achieve this, the mathematical framework of slip inversion suggested by Olson \& Apsel (1982) was adjusted to operate not only with slip sub-sources, but also with convergence sub-sources. From here on, this adjusted method will be called finite source inversion. 
The finite source inversion can provide a perfect fit of the recorded waveforms, while the underlying distribution of convergence or slip may, in fact, be unrealistic (e.g. opposite directions of convergence/slip in the nearest parts of the source, simultaneous initiation of convergence/slip in the distant parts of the source). Furthermore, a similar match between the recorded and modelled waveforms may be attained for different distributions of convergence/ride. Therefore, it is important to constrain the parameters of the inverted finite source to get results that make sense and are unambiguous. We used the following constraints:

- The finite source was assumed to be distributed along a horizontal plane between the undercut and extraction levels within the area where damage was observed. In the current analysis, we did not try to invert the spatial distribution of convergence for the undercut and extraction levels separately, as it may introduce ambiguity. Therefore, the inverted results will characterise the gross motion of the rock mass above the undercut level relative to the rock mass below the extraction level.

- The source was discretised using 30 elements each of $30 \times 30 \mathrm{~m}$ in size (Figure 10).

- The failure was assumed to start at the location of firings preceding the large event (marked in Figure 7) and propagate radially with a velocity of $750 \mathrm{~m} / \mathrm{s}$. The resulting initiation times are shown in Figure 10. The finite source inversion algorithm allows variation of the origin time for each sub-source around the initiation time and extends the duration of sub-source time functions, which is referred as the multi-time-window method in (Ide 2007).

- The seismic waveforms were band pass filtered between 3 and $60 \mathrm{~Hz}$.

The Green's function for a homogeneous and unbounded isotropic medium was used to calculate synthetic seismograms for sub-sources. Therefore, only the waveforms recorded by sites which are located within line-of-sight from the sub-sources were adopted in the inversion.

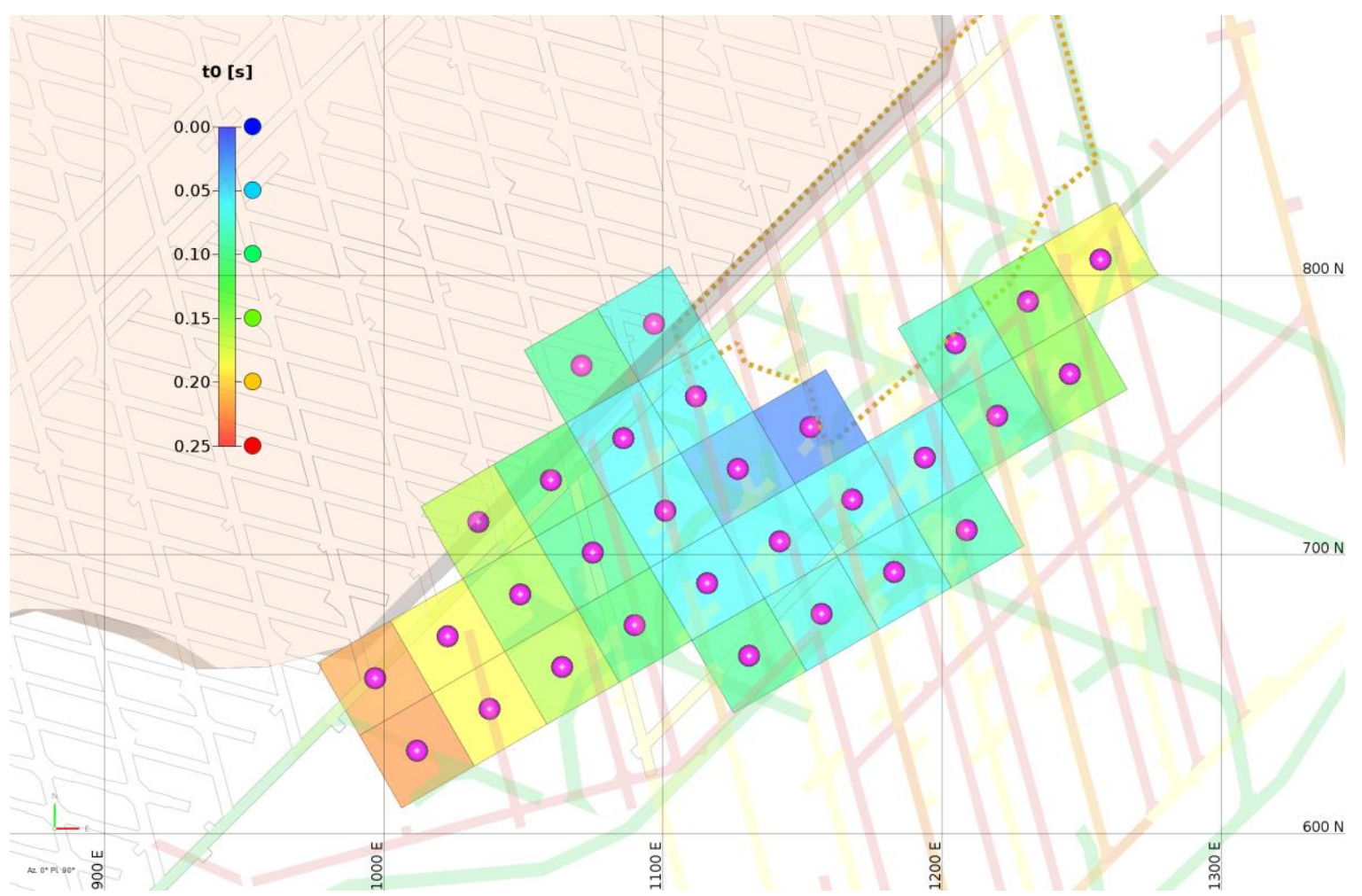

Figure 10 Parametrisation of the finite source. Pink spheres describe 30 point sources distributed along the level $Z=2,113$ (between the undercut and extraction levels). Each of these sources describes convergence and ride of the flat $30 \times 30 \mathrm{~m}$ element, which are shown as a black wireframe. The colour indicates the delay in the time of initiation of the corresponding element 
Results of the calculations are presented in Figure 11. A complete match between the observed and synthetic waveforms was not achieved for the imposed constraints described above. The most significant discrepancy between the observed and modelled waveforms is for $Y$ component at sites 162 and 65 . The mismatch in the tails of waveforms of sites 5 and 155 may be less important as it can be attributed to the scattering of waves or the interaction of seismic waves with the caves, which is not taken into account in the adopted Green's function.
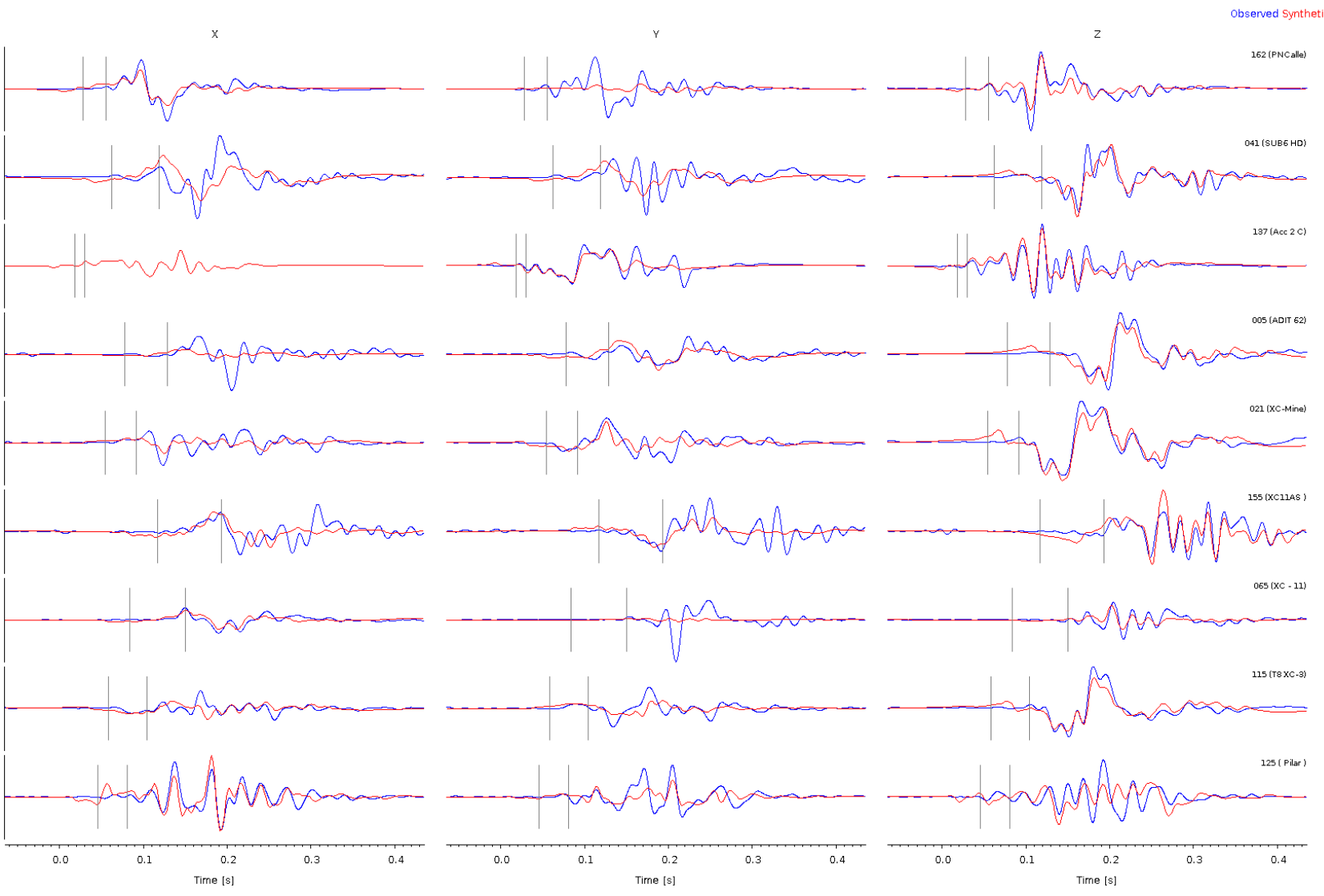

(a)

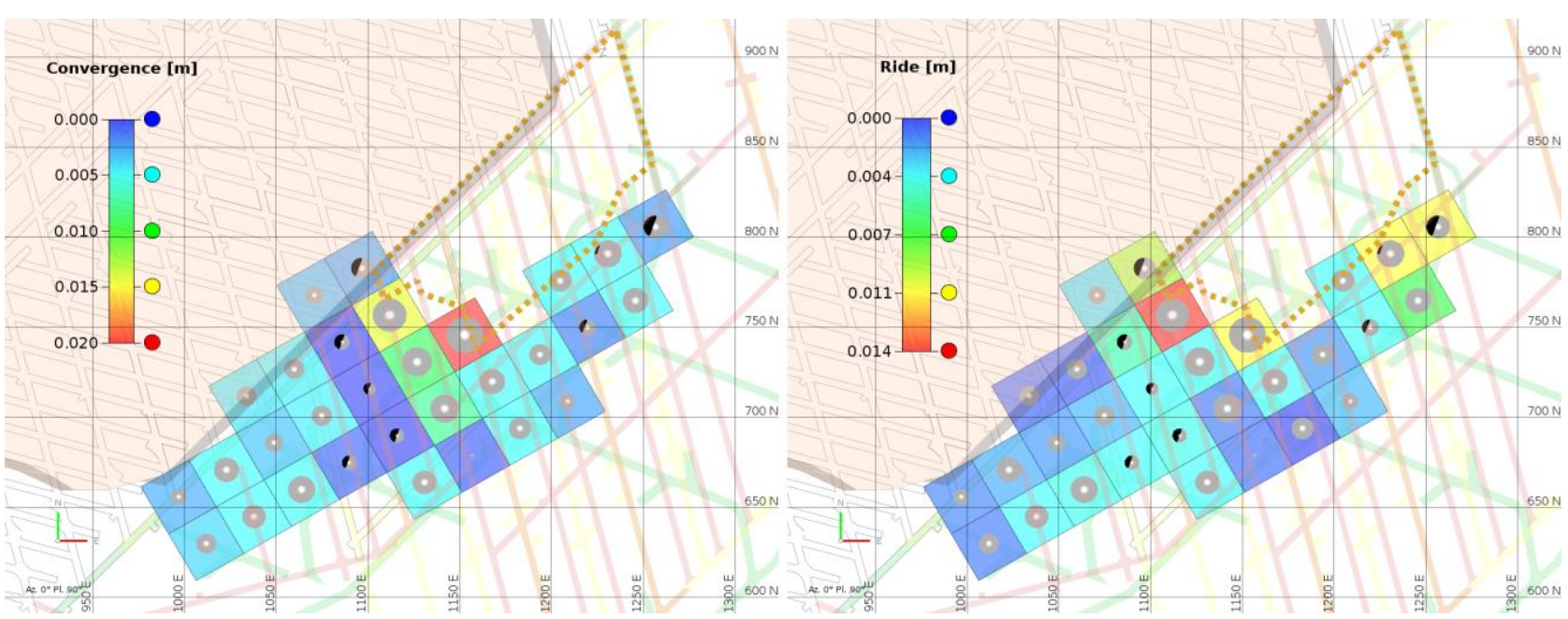

(b)

Figure 11 Results of finite source inversion. (a) Match between the recorded (observed - blue) waveforms, and waveforms modelled for the inverted distributed source (synthetic - red); and, (b) Spatial distributions of total convergence and ride. Beach balls show the type of deformation (white sphere - predominant convergence, double-couple - predominant ride) and direction of ride. The sizes of the beach balls are proportional to the logarithm of convergence/ride 
The main features of the solution (Figure 11(b)) are as follows:

- The largest convergence and ride took place ahead of the southern undercut front of Pilar Norte. The maximum amplitude was $20 \mathrm{~mm}$ for the vertical convergence and $14 \mathrm{~mm}$ for the ride. The ride is oriented in such a way that rock mass above the undercut level moves to the northwest and rock mass below extraction level moves to the southeast (i.e. the ride is driven by compressional stress plunging to the northwest).

- The area ahead of the eastern undercut front of Pilar Norte experienced mainly shearing deformation (significant ride component). The maximum amplitude of ride here is $10 \mathrm{~mm}$.

- The area ahead of the eastern abutment of the Sub 6 cave had similar amplitudes of convergence and ride, of the order of 3-6 mm.

The reconstructed convergence of the order of 10-20 mm may be considered as being too low in relation to the damage observations (Figure 3). This should not be seen as a contradiction. The values presented in Figure 11 characterise elastic convergence and ride, i.e. motion of rock mass above the undercut level relative to rock mass below the extraction level. The closure observed underground may be much larger as it generally includes a significant inelastic component.

Another output of the finite source inversion is presented in Figure 12, which plots the spatial distributions of the maximum rate of vertical convergence and maximum rate of ride for sub-sources. The largest values of convergence rate $(0.6-0.8 \mathrm{~m} / \mathrm{s})$ are attributed to the southern and eastern sides of the Pilar Norte undercut front. In other areas, the rate of convergence is smaller - between 0.2 and $0.4 \mathrm{~m} / \mathrm{s}$. The maximum rate of ride if also high along the southern and eastern undercut fronts of Pilar Norte (above $0.5 \mathrm{~m} / \mathrm{s}$ ). Another area of a similarly high rate of ride is in the south of the distributed source.

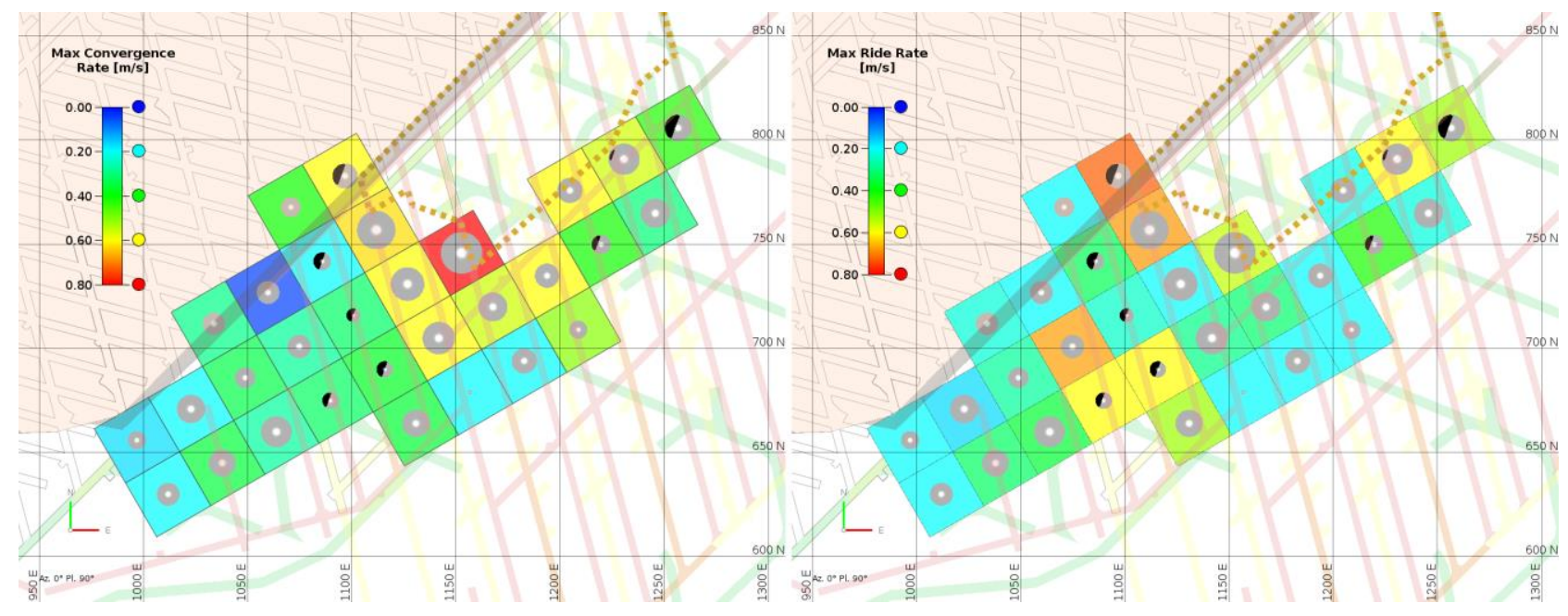

(a)

(b)

Figure 12 (a) Maximum rate of convergence; and, (b) Maximum rate of ride obtained by finite source inversion. The visualisation of mechanisms of sub-sources is the same as in Figure 11

Note the differences between the inversion of moment tensor (Figure 8) and the reconstruction of finite source details (Figure 11). In the first case, the low-frequency part of seismic radiation is used-seismic signals with frequencies from 5-15 Hz, which correspond to the wavelengths from 200-700 m in the case of S-waves. The area of damage, which is hypothesised as a seismic source, has similar dimensions which partly justify the utilisation of a point source model and the inversion of moment tensor for these waves. The finite source inversion operates with seismic signals of higher frequencies (between 5 and $60 \mathrm{~Hz}$ ), which correspond to the wavelengths from 60-700 $\mathrm{m}$ in the case of S-waves. For $60 \mathrm{~m}$ wavelengths, the hypothesised distributed source (damage shown in Figure 9) cannot be considered as a point, and the splitting of the source into smaller sub-sources is required (Figure 10). 
The fact that the minimum adopted wavelengths were of the order of $60 \mathrm{~m}$ introduces ambiguity in the interpretation of results (Figure 13). For example, it is not possible to attribute the reconstructed convergence and ride to a particular level, i.e. it can be related only to the undercut level, or only to the extraction level, or to both of them. Furthermore, the details of failure on the scale of metres and first tens of metres are beyond the resolution of results. The reconstructed convergence and ride may be associated with the variety of damage processes that can happen around the tunnels - pillar foundation failure, side wall failure, failure in the shoulders or corners and even complete pillar failure. The resolution of finite source inversion does not allow to identify which of these damage processes took place in the analysed case.

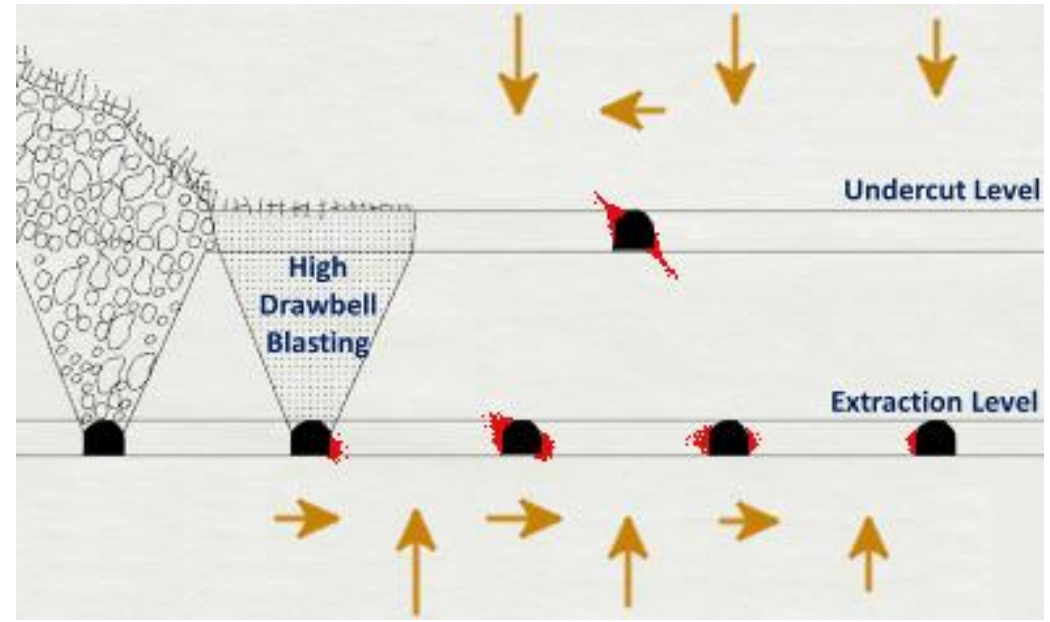

Figure 13 Interpretation of the results of finite source inversion. The high drawbell mining layout is shown in the background. Vertical and horizontal brown arrows indicate the reconstructed convergence and ride, respectively. The arrow lengths are exaggerated (i.e. they do not show the absolute amplitude of displacement). They aim to illustrate spatial variation and directions of the convergence and ride. Possible variants of damage of excavations are marked in red

\section{Conclusion}

The source of the large seismic event on 24 December 2011 likely represents a cascading damage of tunnels of extraction and undercut levels. This hypothesis is supported by the following seismological observations:

- The seismic source mechanisms of medium-sized events recorded in Pilar Norte in 2011 indicate the predominant role of vertical compressional stress in the failure processes in the sources. The mechanisms of seismic events located close to the undercut and extraction levels are mainly of a crush-type, i.e. they have a significant implosive component and a pancake-shaped deviatoric component with sub-vertical P-axis, which suggests vertical convergence of excavations.

- The point source mechanism of the large event evaluated using the low-frequency waveforms is also of a crush-type.

- The higher frequency part of waveforms of the large event can be modelled by a combination of point sources having a closing crack and riding mechanisms distributed in a horizontal plane $(\mathrm{Z}=2,113 \mathrm{~m})$ within the area where damage was observed underground. The failure started around the southern undercut front of Pilar Norte and propagated to other areas of damage in $250 \mathrm{~ms}$.

The hypothesis of the cascading damage of tunnels agrees with other data mentioned in Sections 2 and 3:

- More than $90 \%$ of observed damage was attributed to the side walls of tunnels.

- Although the maximum principal in situ stress is sub-horizontal, stress modelling indicates that the local stress around the tunnels of the extraction level is sub-vertical.

The presented results serve to illustrate that the assessment of seismic loading to excavations based on a point seismic source model and ground motion prediction equation may be misleading. Assuming a point seismic source co-located with moment tensor centroid (Figure 9) and adopting ground motion prediction 
equations of McGarr (1984), and Kaiser and Maloney (1997), the PPV/PGV of the order of $40-65 \mathrm{~mm} / \mathrm{s}$ is expected at the places of damage around the eastern Pilar Norte undercut front and eastern Sub 6 abutment (100-150 $\mathrm{m}$ from the point source). The reconstructed characteristics of distributed source indicate the rate of elastic convergence and ride at that locations was an order of magnitude higher $-0.4-0.6 \mathrm{~m} / \mathrm{s}$.

When seismic events associated with a rockburst need to be analysed, it is recommended to start with the consideration of the hypothesis of a self-initiated rockburst. The kinematic and dynamic characteristics of recorded seismic waveforms can be compared with the characteristics of seismic signals expected to be radiated by the observed episodes of excavation damage. If the recorded waveforms cannot be explained by the rockburst mechanism, then the alternative scenario of remotely induced or triggered rockburst needs to be investigated. At that stage, a point seismic source model and ground motion prediction equation may be useful for the assessment of seismic loading at the locations of damage.

\section{Acknowledgement}

Stephen Meyer from the Institute of Mine Seismology helped to improve the text of the paper. Comments and suggestions from the reviewers are appreciated.

\section{References}

Aki, K \& Richards, P 2002, Quantitative Seismology, 2nd edn, University Science Books, Herndon, 700 p.

Bolt, BA \& Abrahamson, NA 2003, 'Estimation of strong seismic ground motions', in WHK Lee, H Kanamori, PC Jennings \& C Kisslinger (eds), International Handbook of Earthquake and Engineering Seismology, vol. B, Academic Press, Cambridge, pp. 983-1001.

Dunlop, R \& Belmonte, A 2005, 'The April 22nd, 2003 rockburst in the Sub 6 sector, El Teniente mine - A case study', in Y Potvin \& M Hudyma (eds), Proceedings of the 6th International Symposium on Rockbursts and Seismicity in Mines, Australian Centre for Geomechanics, Perth, pp. 291-297.

Hanks, TC \& Kanamori, H 1979, 'A moment magnitude scale', Journal of Geophysical Research, vol. 84, no. 5, pp. $2348-2350$.

Ide, S 2007, 'Slip inversion', in G Schubert (ed), Treatise on Geophysics, Volume 4: Earthquake Seismology, Elsevier, New York, pp. 193-223.

Kaiser, PK \& Maloney, SM 1997, 'Scaling laws for the design of rock support', Pure and Applied Geophysics, vol. 150, no. 3-4, pp. 415-434.

Kaiser, PK, McCreath, DR \& Tannant, DD 1996, Canadian Rockburst Support Handbook, Canadian Mining Industry Research Organization, Sudbury.

Leiva, CE \& Duran, L 2003, 'Pre-caving, drilling and blasting in Esmeralda Sector of El Teniente mine', Fragblast, vol. 7, no. 2, pp. 87-104.

Malovichko, D \& Meyer, S 2017, El Teniente Mine: Analysis of Influence of Mining Factors on Seismic Hazard Characteristics in the Reservas Norte Sector, technical report, Institute of Mine Seismology, Hobart, $56 \mathrm{p}$.

Malovichko, D, van Aswegen, G \& Clark, R 2012, 'Mechanisms of large seismic events in platinum mines of the Bushveld Complex (South Africa)', The Journal of The Southern African Institute of Mining and Metallurgy, vol. 112, pp. 419-429.

McGarr, A 1984, 'Scaling of ground motion parameters, state of stress, and focal depth', Journal of Geophysical Research, vol. 89, no. B8, pp. 6969-6979.

Mendecki, AJ 1997, Seismic Monitoring in Mines, Chapman and Hall, London, 262 p.

Olson, A \& Apsel, R 1982, 'Finite faults and inverse theory with applications to the 1979 Imperial Valley earthquake', Bulletin of the Seismological Society of America, vol. 72, pp. 1969-2001.

Rojas, E \& Balboa, S 2017, 'Keynote lecture: Management of seismic risk in high stress conditions, El Teniente mine', in JA Vallejos (ed), Proceedings of the 9th International Symposium on Rockbursts and Seismicity in Mines, University of Chile, Santiago, pp. 280-289.

Vavrycuk, V \& Kuhn, D 2012, 'Moment tensor inversion of waveforms: a two-step time-frequency approach', Geophysical Journal International, vol. 190, no. 3, pp. 1761-1776.

Wiles, T 2010, Map3D, computer software, Map3D International Ltd, https://www.map3d.com 